\title{
Study on Absenteeism among Children in School
}

\author{
Ms. Charu Sethi \\ Department of Social Work, University of Delhi India
}

\begin{abstract}
There are number of studies that document the importance of regular school attendance. There is a consensus among authors that absenteeism has negative implications for academic achievement as well as the social development of the child. Most of the existing studies have focused on school absenteeism among children and adolescents with poor school performance. This paper addresses this gap in research by exploring factors that are related to school absenteeism in Inclusive school. The findings indicate that a combination of institutional and individual factors shape patterns of poor school attendance in Inclusive schools.
\end{abstract}

Keywords: Chronic Absenteeism, Inclusive School, Interest of students, Role of parents, Truancy.

\section{Introduction}

Absenteeism ' is a common feature in schools. It is the number of students who are not in class on any given day. Chronic truancy (regular unexcused absence), in particular, is a predictor of undesirable outcomes in students, including academic failure, school drop out, substance abuse, and gang and criminal activity.

Students need to attend school daily to succeed.

Attendance also strongly affects standardized test scores and graduation and dropout rates. Educators and policymakers cannot truly understand achievement gaps or efforts to close them without considering chronic absenteeism.

Chronic absenteeism is not the same as truancy or average daily attendance - the attendance rate schools use for state report cards and federal accountability. Chronic absenteeism means missing 10 percent of a school year for any reason. A school can have average daily attendance of 90 percent and still have 40 percent of its students chronically absent, because on different days, different students make up that 90 percent. Shiu, S. $(2001)^{5}$

Chronic absenteeism is most prevalent among low-income students. Gender and ethnic background do not appear to play a role in this. The youngest and the oldest students tend to have the highest rates of chronic absenteeism, with students attending most regularly in third through fifth grades. Chronic absenteeism begins to rise in middle school and continues climbing through 12th grade, with seniors often having the highest rate of all.

Students miss school for many reasons. These can, however, be divided into three broad categories:

- Students who cannot attend school due to illness, family responsibilities, housing instability, the need to work or involvement with the juvenile justice system.

- Students who will not attend school to avoid bullying, unsafe conditions, harassment and embarrassment.

- Students who do not attend school because they, or their parents, do not see the value in being there, they have something else they would rather do, or nothing stops them from skipping school.

Despite being pervasive, though overlooked, chronic absenteeism is raising flags in some schools and communities. This awareness is leading to attendance campaigns that are so vigorous and comprehensive they pay off quickly. Examples of progress nationally and at state, district, and school levels give hope to the challenge of chronic absenteeism, besides being models for others.

\section{The top reasons children miss school}

2.1 Illness Parents who are chronically ill have difficulty getting their child to school regularly and on time. If the child is chronically ill, they may be more apt to miss due to being sick or having doctor appointments. Urban public schools usually see a large number of chronic health issues ranging from asthma to diabetes, to obesity. 2.2 Moving Some families, especially those in poverty, tend to move a lot. They may move due to foreclosure, eviction or family crisis. Often when a family moves, the child is out of school for several days. The academic and emotional toll is significant, studies show. 2.3 Poverty Poverty brings a host of problems that cause kids to miss school: Lack of reliable transportation; no money for school clothes; or parents working more than one job or overnight shifts who are unable to get their children on the bus in the morning. Many are also single parents without afety net. 2.4 Safety Some students stay home or leave class early to avoid bullying or other social problems. Some may not feel safe on the bus or on the walk to school. 2.5 Motivation Some students are 
chronically absent simply because their family hasn't made education a priority. If parents didn't grow up with attendance being a priority, they may not stress the importance to their children. But being even 10 minutes late

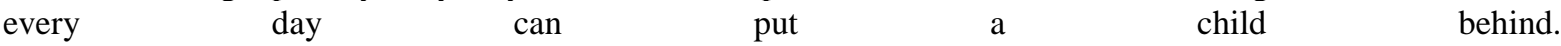

School refusal behavior is an illegitimate absenteeism or, more specifically, to child-motivated refusal to attend school or difficulty attending classes or remaining in school for an entire day. The behavior is often manifested by a spectrum of absenteeism that includes complete absence for long periods of time, partial absences due to skipping classes or missing part of a school day, chronic tardiness, and sporadic or full-time school attendance marked by substantial dread about going to school and pleas to parents and others to remain home from school. Thus, school refusal behavior includes youths who are actually missing school as well as those who wish to miss school but who have not yet reached this goal.

\section{Review of literature}

Chronic absenteeism is a problem that has plagued the school system for a number of years. The cost of missed days of school can be counted in missed work, missed participation, and missed opportunities. The chronically absent student falls behind his/her peers academically which may lead to grade level retention and truancy.

Truancy has been identified as one of the key indicators associated with students who drop out of public schools. Truancy can also be a predictor of illegal drug use by students. S. Mayor. (2005) ${ }^{4}$

Researchers have attempted to identify the various characteristics of truant or chronically absent students.

Studies indicated that socioeconomic status and enrollment in the exceptional education program may be indicators for chronic absenteeism (FDOE, 2004a). Still others have indicated that certain types of disciplinary action used in the school may also indicate the level of chronic absenteeism and truancy (K. Hoffman, C. Llagas, \& T. D. Snyder, 2003) ${ }^{6}$.

School teachers and administrators have attempted to combat the problem of chronic student absenteeism through rules, consequences, and programs. (R. Sapien, \& N. Allen, 2004) ${ }^{3}$

In spite of these efforts, students still miss school. Externally imposed consequences for students who are chronically absent have yielded questionable results (J. Lightfoot, S. Muckherjee, P. Sloper, 2001) ${ }^{7}$. The use of punitive consequences to address the chronic absenteeism and truancy problem have been found to yield short-term results, but only as long as the punitive consequences are in place (G. Reid, 2005) 9 .

There are evidences that handicapped students attending regular schools are no more likely to be absent from school than non-handicapped students (J. W. McDaniel, 1983) ${ }^{10}$. High rates of school attendance do not necessarily ensure high rates of programme attendance or achievement. Sullivan \& McDaniel concluded that children served in resource rooms may be receiving up to one quarter less schooling time than is prescribed in their individualized education programmes because of competing school activities and absences of either the resource room teacher or the student during a scheduled period.

Cognitive effects have been researched among specific chronic health conditions such as diabetes and cancer. Examination of neurodevelopment among early onset type 1diabetes results, indicating lower nonverbal intelligence and slower psychomotor speed in adults who developed diabetes before the age of seven. Cognitive deficits and problems in school functioning have also been shown $\mathrm{o}=$ in children with sickle cell disease ( $\mathrm{S}$. Powers, S. Patton, K. Hommel \& A. Hershey $(2003)^{8}$.

According to the National Center for Education Statistics for 2005, $19 \%$ of fourth-graders and $20 \%$ of eighth-graders missed at least 3 days of school in the past month. More specifically, $7 \%$ of fourth-graders and $7 \%$ of eighth-graders missed at least 5 days of school in the past month. School absenteeism is largely unrelated to gender but more common among diverse students, especially American Indians, as well as students with disabilities. (Christopher A. Kearney, 2008) ${ }^{1}$

There are risk factors associated with not attending school that include family background and relationships, past school performance, personal characteristics, and school or neighborhood characteristics. For instance, home dynamics such as impoverished living conditions, frequent home relocations, lack of child supervision, and other family issues are often related to non-attendance (K. Reid, 2011) ${ }^{2}$

\section{Need for conducting the study:}

Researcher was curious to know absenteeism in a particular school setting in lieu of this the Researcher chose to focus on a Private School (Inclusive school). So eventually this research project was started to study the factors behind absenteeism as school attendance is the important factor for school performance among students.

As younger students, are not responsive to the questions, the students of class VIth, VIIth and VIIIth were chosen for the study. 


\section{Objectives of the study}

The main objective of the initiative is to generate among parents of the students an interest in the child's school life- curricular and co curricular activities - improving their performance and inculcating an interest in studies.

In the study an endeavor has been made as-

- To identify the causes/ reasons for absenteeism among students.

- To suggest ways and means by which the school can play a positive role in decreasing the problem of absenteeism among children.

- Aware parents about the importance of attendance.

\section{Method}

Scope: The study of absenteeism among children in a Private School is restricted to the students studying in class VIth, VIIth and VIIIth.

The Descriptive research design was used in the present study. The study was conducted by use of the interview schedules through personal interviews with students studying in class- VIth, VIIth and VIIIth and their parents.

\section{Results and Discussion}

The above gathered data was compared with the absenteeism rate of the children from July, 2011 to December, 2011 and following conclusions were drawn-

The sample constitutes 60 parents of the children of class VI, VII and VIII. Majority of parents (45\%) were of class VII children and rest $40 \%$ and $15 \%$ were parents of the children of class VI and VIII respectively.

7.1 The findings reveal that absenteeism among children is not due to the disability per se because the figures show that around equal percentage of children who are not physically disable and other who are differently abled have been absent. There is not much difference between the absenteeism rate among children with disability and children without disability as the attendance record of the children proves the fact. Thus absenteeism can not be attributed to disability.

7.2 The study further reveals that those parents who regularly monitor their children, knowing about the child's day and school activities, are serious towards their development, those children show low rate of absenteeism. This justifies the fact that proper interest of the parents in the education of the children motivates them to study, they are aware of the need to get educated and make a career.

7.3 Moreover, same is seen with the monetary aspects. Those parents who do not spend good amount of money in the proper nurturing of their children and are not concern about the needs of the child, those children regularly miss the school and show high rate of absenteeism.

7.4 It is also seen that due to household work, family engagements, meeting relatives prevent children from attending the school. On a single holiday say Sunday, if child went to his relatives place with the family then it is a possibility that they may spend more days and child would be absent those days from the school. This throws the light on the fact that if parents want children to be educated then they need to change their attitude and prevent children to get more involved with the house hold work and other engagements rather motivate them to regularly attend the school.

7.5 Parents who do not encourage children to move upward in life, do not motivate children to build their aims and ambitions and provide an environment which suppress them to dream their aims and are not motivated reveal high rate of absenteeism. Thus, if such an environment is facilitated in homes at large, then probably problem of absenteeism can not be attended to.

7.6 In the direct question on the reason of being absent, major portion of the parents stressed the fact that their child is absent due to illness, whereas, disinterest ness of the child towards studies was other factor. This fact can be taken as a suggestion as to provide better medical facilities to children from near by hospital and creative and interesting teaching mechanisms should be used to motivate parents to send their children to school.

\section{Suggestions gained by the parents to curtail absenteeism rate}

a. There should be improved standard of teaching; teachers should use innovative means, teaching aids (charts, models, maps, videos) to teach children so that children also enjoy and take interest in learning. Relationship of students and teacher was also focused, as there should be a comfort level between them.

b. Different awards can be given, for instance- prize for the most regular child of the school, prize for punctual child etc- these awards will motivate children for the regular schooling. 


\section{Role of the Counselor in minimizing the absenteeism rate}

- Identify skill teachers, sessions with teachers to enable them to adopt creative ways of teaching.

- Home visits to see why child is not coming to school. Hold parent meetings, make home visits and stay in touch with families to make sure they are getting the help they need so their children make it to school.

- Making children aware about the importance of education in life, keeping the success stories in front of them.

- Organizing sessions and awaring people about the importance of regular schooling and education.

Journals

\section{References}

[1]. Christopher A. Kearney, School absenteeism and school refusal behavior in youth: A contemporary review Volume 28, Issue 3, March 2008, Pages 451-471

[2]. K. Reid, The self-concept and persistent school absenteeism: British Journal of Educational Psychology Volume 52, Issue 2, June 1982, Pages 179-187,

[3]. R. Sapien, \& N. Allen, Teaching school teachers to recognize respiratory distress in asthmatic children: Journal of Asthma, 41(7), 739-743.

[4]. [4] S. Mayor, Extremely low birth weight is linked to risk of chronic illness. British Medical Journal, 331, 180. (2005)

[5]. S. Shiu, Issues in the education of students with chronic illness. International Journal of Disability,

[6]. Development, and Education, Volume 16, Issue 3, March 2011, Pages 136- 145.

[7]. K. Hoffman, C. Llagas, \& T. D. Snyder, The Influence of Cultural, Social Identity and Educational Factors on Academic Achievement Among African American High School Males: A Preliminary Study, 22 - 53(2003).

Books

[8]. J. Lightfoot, S. Muckherjee \& P. Sloper, Supporting pupils with special health needs in mainstream schools: Policy and practice. Children \& Society, 15, 57-69 (2001).

[9]. S. Powers, S. Patton, K. Hommel \& A. Hershey, Quality of life in childhood migraines: clinical impact and comparison to other chronic illness, 2003.

[10]. G. Reid, Learning Styles and Inclusion (2005) Theses

[11]. J. W. McDaniel, An assessment of utility of the cognitive concept in intercultural communication research. 432 (8), 132- 165 (1983). 